\title{
Interferencia de Malezas en el Cultivo de FriJol en dos SisTEMAS DE LABRANZAS ${ }^{1}$
}

\author{
Weeds Influence in Bean Crop in Two Tillage Systems
}

PARREIRA, M.C. ${ }^{2}$, PEÑAHERRERA-COLINA, L.A. ${ }^{3}$, ALVES, P.L.C.A. ${ }^{4}$ y PEREIRA, F.C.M. ${ }^{5}$

\begin{abstract}
RESUMEN - Con este trabajo, se busco determinar el período anterior a la interferencia de las malezas que conviven con el cultivo de frijol, en ausencia o presencia de residuos vegetales de Crotalaria juncea. Los tratamientos estaban constituidos de siete períodos de convivencia del cultivo con las malezas: 0-10, 0-20, 0-30, 0-40, 0-50, 0-60 y 0-70 días después de la emergencia y también de un testigo sin presencia de las malezas en ausencia o presencia de crotalaria. El diseño experimental utilizado fue de bloques completos seleccionados al azar, con cuatro repeticiones por tratamiento. Hubo reducciones de 40,6\% y 55,1\% en la productividad de granos de frijol en convivencia con malezas durante todo el ciclo del cultivo, en ausencia y presencia de los residuos vegetales, respectivamente. Se concluyó que la productividad de granos fue afectada negativamente a partir de 29 y 38 días después de la emergencia, sin y con residuos, respectivamente, y eso constituyó los períodos anteriores a la interferencia.
\end{abstract}

Palabras clave: Phaseolus vulgaris, abono verde, períodos de interferencia.

\begin{abstract}
The research aim to determine the period prior to weed interference on common beans (Phaseolus vulgaris). The treatments had been made out of seven periods of coexisting by the culture with the weed $0-10,0-20,0-30,0-40,0-50,0-60$, and 070 days after crop emergence in absence and presence crop residue. It had reduction of $40.56 \%$ and $55.12 \%$, the productivity of grains in the culture of the common bean when the coexistence with the weed was during all the cycle of the culture, in absence and presence crop residue, respectively. It was concluded that grain yield was negatively affected from the $29^{\text {th }}$ and $38^{\text {th }}$ days after emergence, in the absence and presence of crop residue, respectively.
\end{abstract}

Keywords: Phaseolus vulgaris, crop residue, period interference.

\section{INTRODUCCIÓN}

Para obtener una buena productividad, el suministro de nutrientes es fundamental, principalmente de nitrógeno. Por ser un cultivo exigente en términos nutricionales, el frijol necesita nutrientes adecuados y suficientes para que su producción sea satisfactoria (Malavolta, 1979).
Crotalaria juncea es una especie muy utilizada como abono verde, posee semillas de fácil obtención, sin período de dormancia, de crecimiento rápido y gran competitividad; raíces profundas y vigorosas, capaces de reciclar nutrientes; es resistente a plagas y poco atacada por enfermedades; $y$, principalmente, fija nitrógeno del aire (Alvarenga et al., 1995). El cultivo de abonos verdes, como

1 Recebido para publicação em 19.8.2012 e aprovado em 16.11.2012.

2 Eng-Agr ${ }^{\mathrm{a}}$., Doutoranda em Agronomia (Produção Vegetal), Laboratório de Plantas Daninhas (LAPDA), FCAV/UNESP, Jaboticabal, SP, <mariana.casari@posgrad.fcav.unesp.br>; ${ }^{3}$ Engo-Agro ., Doutorando em Agronomia (Produção Vegetal), Núcleo de Estudos e Pesquisas Ambientais em Matologia (NEPEAM), FCAV/UNESP, Jaboticabal, SP; ${ }^{4}$ Professor Adjunto do Dep. de Biologia Aplicada à Agropecuária, FCAV/UNESP, Jaboticabal, SP; ${ }^{5}$ Engà-Agr ${ }^{\mathrm{a}}$., Doutoranda em Agronomia (Produção Vegetal), Laboratório de Plantas Daninhas (LAPDA), FCAV/UNESP Jaboticabal, SP. 
el de leguminosas, en sistema de siembra directa, ha demostrado ser una excelente opción para la adición de nitrógeno (Gonçalves et al., 2000).

La productividad del cultivo de frijol puede reducirse por la interferencia de las malezas de 15 a 97\%, de acuerdo con el cultivar, época de siembra, composición y densidad de las especies cultivadas (Lunkes, 1997; Scholten et al., 2011).

Los abonos verdes controlan las malezas de tres maneras principales: a través de la competencia por agua, nutrientes, luz y espacio durante su crecimiento; por medio de alelopatía en la germinación de semillas y desarrollo de plántulas; y por efecto físico de los residuos vegetales que producen sombra, lo que impide que las semillas de las malezas reciban estímulos para germinar (Espíndola et al., 2005).

El frijol es una planta con ruta fotosintética $_{3}$, que se desarrolla mejor en temperaturas moderadas y presenta bajo punto de compensación luminoso (Willian, 1973). Por ser una planta con un período de crecimiento vegetativo corto, es sensible a interferencia de las malezas en el inicio de su desarrollo y compite por factores esenciales como luz, espacio y nutrientes (Cobucci et al., 1999).

Para Pitelli y Durigan (1984), el período anterior a la interferencia es un espacio de tiempo a partir de la siembra o emergencia en que el cultivo puede convivir con la comunidad de malezas sin sufrir efectos negativos en su productividad. Cuanto mayor es el período de convivencia del cultivo con las malezas, cuando ambos disputan los recursos del medio, mayor será el grado de interferencia, que perjudica al cultivo de forma significativa (Pitelli, 1985).

El objetivo de este trabajo fue determinar el período anterior a la interferencia de las malezas (PAI) en el cultivo de frijol en presencia y ausencia de residuos vegetales de Crotalariajuncea.

\section{MATERIALES Y MÉTODOS}

E1 ensayo se realizó en condiciones de campo, en la ciudad de Jaboticabal-SP, Brasil, en el año 2008. El suelo está clasificado como Latossolo Vermelho Escuro, de textura arcillosa, cuyo análisis granulométrico y químico se presentan en las Tablas 1 y 2 .

E1 ensayo fue dividido en dos áreas: la primera con residuos vegetales de crotalária (Crotalaria juncea) y la segunda sin labranza y con malezas.

Se realizaron muestreos quincenales de las malezas en las áreas. La comunidad estaba compuesta por: Cyperus rotundus, Commelina benghalensis, Xanthium strumarium, Amaranthus deflexus, Raphanus raphanistrum, Indigofera hirsuta, Cenchrus echinatus, Eleusine indica, Portulaca oleracea, Alternanthera tenella, Phyllanthus tenellus, Ipomoea grandifolia y Cardiospermum halicacabum.

Después de que las plantas de crotalaria iniciaron su floración, aproximadamente dos

Tabla 1 - Resultados del análisis físico de suelo del área experimental

\begin{tabular}{|c|c|c|c|c|}
\hline \multirow{2}{*}{ Arcilla } & \multirow{2}{*}{ Limo } & \multicolumn{2}{|c|}{ Arena } & \multirow{2}{*}{ Clase } \\
\cline { 3 - 4 } & & Fina & Gruesa \\
\hline \multicolumn{3}{|c|}{$\left(\mathrm{g} \mathrm{kg}^{-1}\right)$} & 90 & Arcillosa \\
\hline
\end{tabular}

Tabla 2 - Resultados del análisis químico del suelo del área experimental

\begin{tabular}{|c|c|c|c|c|c|c|c|c|c|}
\hline $\mathrm{pH}$ & MO & P resina & $\mathrm{K}$ & $\mathrm{Ca}$ & $\mathrm{Mg}$ & $\mathrm{H}+\mathrm{Al}$ & \multirow{2}{*}{ SB } & \multirow{2}{*}{$\mathrm{T}$} & V \\
\hline$\left(\mathrm{CaCl}_{2}\right)$ & $\left(\mathrm{g} \mathrm{dm}^{-3}\right)$ & $\left(\mathrm{mg} \mathrm{dm}^{-3}\right)$ & \multicolumn{4}{|c|}{$\left(\mathrm{mmol} \mathrm{dm}{ }^{-3}\right)$} & & & $(\%)$ \\
\hline 5,4 & 25 & 6,3 & 2,7 & 33 & 13 & 31 & 48,7 & 79,7 & 61 \\
\hline
\end{tabular}


meses tras la siembra, ellas fueron cortadas con triton, acoplado a un tractor, con el fin de distribuir los residuos vegetales en el área sólo donde estaban las plantas de crotalarias - de manera uniforme. Quince días después, se realizó un pase de arado y dos de rastra, en las dos aéreas, incluso el área sin labranza. Transcurridos 5 días de la preparación del suelo, se realizó la siembra del frijol en el cultivar Pérola, en el sistema convencional, utilizando una densidad de 15 semillas por metro linear, para todo el ensayo.

Para las dos áreas, las unidades experimentales se constituyeron por cinco líneas de siembra de frijol con espaciamiento de $0,45 \mathrm{~m}$ por $8,0 \mathrm{~m}$ de largo. El área resultante fue de $18 \mathrm{~m}^{2}$, pero se consideró borde las dos líneas externas de cada parcela experimental, y el área útil estaba constituida por las tres lineas centrales de cada parcela, lo que resultó $10,8 \mathrm{~m}^{2}$ para cada tratamiento.

Los tratamientos experimentales estaban compuestos por siete períodos de convivencia del cultivo con las malezas: 0-10, 0-20, 0-30, 0-40, 0-50, 0-60 y 0-70 días después de la emergencia, y también por un testigo sin malezas, en ausencia y presencia de residuos de crotalaria. Se utilizó el diseño experimental de bloques completos al azar, con cuatro repeticiones por tratamiento.

Noventa y ocho dias después de la siembra o 93 dias tras la emergencia, fueron colectadas manualmente las plantas de frijol de las líneas centrales de cada parcela. Se cosechó las plantas cuando la humedad de los granos era de casi $13 \%$, determinada en estufa con circulación forzada de aire a $105^{\circ} \mathrm{C}\left( \pm 3{ }^{\circ} \mathrm{C}\right)$ por 24 hora, pesando las muestras antes y después de secas en balanza de precisión de 0,01 g. Se desgranaron las vainas de forma mecánica, utilizando una trilladora de granos Nogueira. Los granos colectados fueron pesados en balanza de precisión de 0,01 g.

Se evaluó la importancia relativa (IR) de la comunidad, que es un indice que comprende tres factores: constancia relativa, densidad relativa y dominancia relativa, según fórmulas propuestas por Mueller-Dombois y Ellemberg (1974). Se realizó la densidad y la masa seca de las malezas con la producción de acordó con Kuva et al. (2000). Se calculó la productividad de granos del frijol $\left(\mathrm{kg} \mathrm{ha}^{-1}\right)$ y la masa de 100 granos.

El análisis de los datos de productividad y los resultados de la masa de granos fueron sometidos al análisis de regresión por el modelo sigmoidal de Boltzman.

Utilizando las ecuaciones de regresión, se determinó los períodos anteriores a la interferencia de las malezas para el nivel arbitrario de tolerancia de $5 \%$ de reducción en la productividad de frijol, con relación al tratamiento mantenido en la ausencia de las malezas. En la realización de los análisis de regresión, se utilizó el programa Origin ${ }^{\circledR} 8$ (ORIGINALLAB CORPORATION, USA).

\section{RESULTADOS Y DISCUSIÓN}

Las especies con más importancia relativa en el área $\sin$ los residuos vegetales fueron Raphanus raphanistrum (85,2\%), Cyperus rotundus (3,82\%) y Amaranthus deflexus (3,1\%), que representaban $92,1 \%$ de las plantas de la comunidad. En la presencia de residuos vegetales las especies, los más importantes fueron Raphanus raphanistrum (49,7\%), Cyperus rotundus $(9,8 \%)$ y Digitaria horizontalis $(7,9 \%)$, que representaban $67,4 \%$ de plantas de la comunidad (Figura 1). Se observó mayor importancia relativa de gramíneas, por ejemplo: Panicum maximum, Brachiaria plantaginea y Eleusine indica en el área con presencia de residuos vegetales (Figura 1). Este hecho se debe a que la mayor provisión de nitrógeno en el área por la crotalaria, teniendo en cuenta que las gramineas requieren mayor cantidad de esse elemento mineral para desarrollarse.

Las gramíneas requieren mayor cantidad de nitrógeno. En niveles adecuados, él promueve vigor, calidad visual y recuperación de daños (Bowman et al., 2002). El efecto más conocido de la aplicación de $\mathrm{N}$ en gramíneas es un aumento del crecimiento de la parte aérea y de la intensidad de la coloración verde en las hojas, además de un incremento en el crecimiento de raíces y producción de rizomas (Carrow et al., 2001).

Severino y Christoffoleti (2001) observaron que residuos vegetales de Crotalaria juncea incorporados o en la superficie del suelo aumentaron sensiblemente la densidad de 


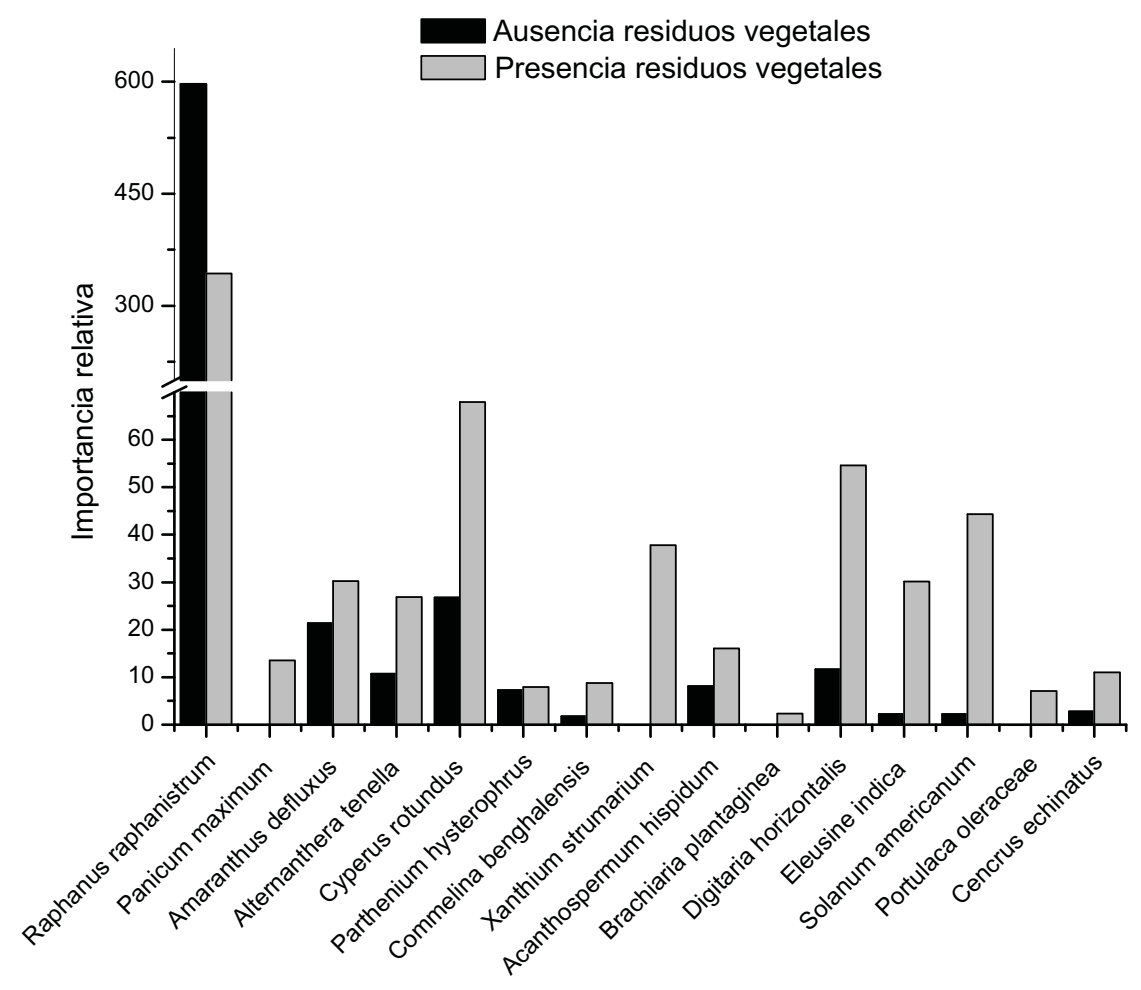

Figura 1 - Importancia relativa (\%) de las malezas de la comunidad.

Bidens pilosa en el área. El manejo del suelo con crotalaria en el cultivo de frijol de inverno, ofreció mayor supresión de las malezas en el área (Vincensi et al., 2011).

Jakelaitis et al. (2003) verificaron una mayor importancia relativa de malezas dicotiledóneas cuando trabajaban con frijol cultivar Sangue de boi en sistema de siembra directa, en la época lluviosa. Kozlowski et al. (2002), al investigar en el cultivo de frijol FT Nobre, en la época de lluvias, en igual sistema de siembra, con residuos vegetales de trigo, observaron la presencia de $61 \%$ de dicotiledóneas, entre las que se destaca Bidens pilosa con el mayor porcentaje (38\%). Las monocotiledóneas, con 39\%, de presencia, fueron Digitaria horizontalis y Brachiaria plantaginea que obtuvieron los mayores porcentajes, con 14 y $23 \%$ respectivamente.

Las mayores densidades de malezas fueron alcanzadas en el período de 20 a 60 dias después de la emergencia (DDE). En el área sin de residuos vegetales, se obtuvo la máxima densidad a los 20 DDE con 340 plantas $\mathrm{m}^{-2}$; y en el área con residuos vegetales, se alcanzó la densidad máxima a los 50 DDE con 140 plantas $\mathrm{m}^{-2}$. Las menores densidades de malezas en áreas sin residuos vegetales ocurrieron a los 70 DDE con 92 plantas $\mathrm{m}^{-2}, \mathrm{y}$ con el presente trabajo, la densidad mínima fue alcanzada a los $20 \mathrm{DDE}$ con 52 plantas $\mathrm{m}^{-2}$. Según Meschede et al. (2004), los flujos iniciales de germinación de las malezas, que ocurren después de la siembra del cultivo, son los de mayor intensidad y densidad, muy importantes con relación a la interferencia inicial, pues imponen al cultivo una situación de restricción de recursos prematuramente.

De las especies más frecuentes, las mayores densidades fueron representadas por Raphanus raphanistrum con 260 plantas $\mathrm{m}^{-2}$ a los 20 DDE y 140 a los 50 DDE, en las áreas con ausencia y presencia de residuos vegetales, respectivamente (Figura 2). Originaria de Europa meridional, Raphanus raphanistrum presenta amplia distribución por las regiones templadas y subtropicales del mundo. Estudios indican que la planta posee substancias que pueden inhibir la germinación de otras especies (Kissmann y Groth, 1999; Lorenzi, 2006). 
Ausencia de residuos vegetales

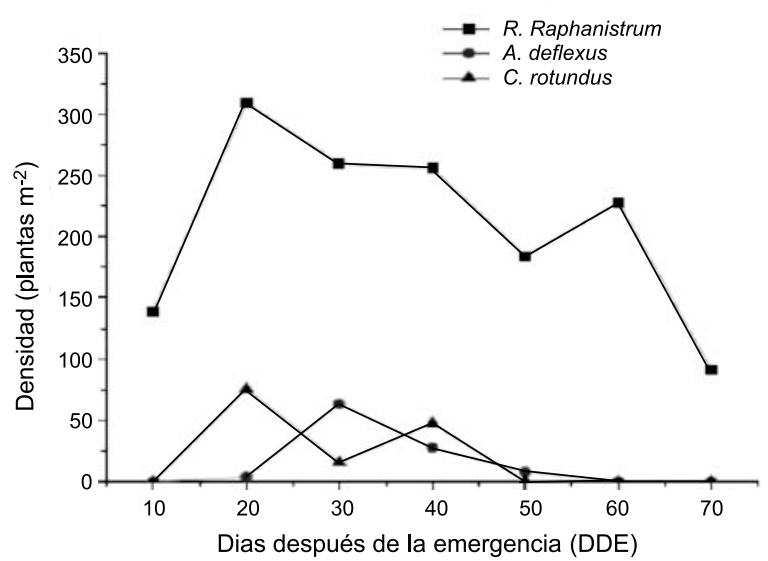

Presencia de residuos vegetales

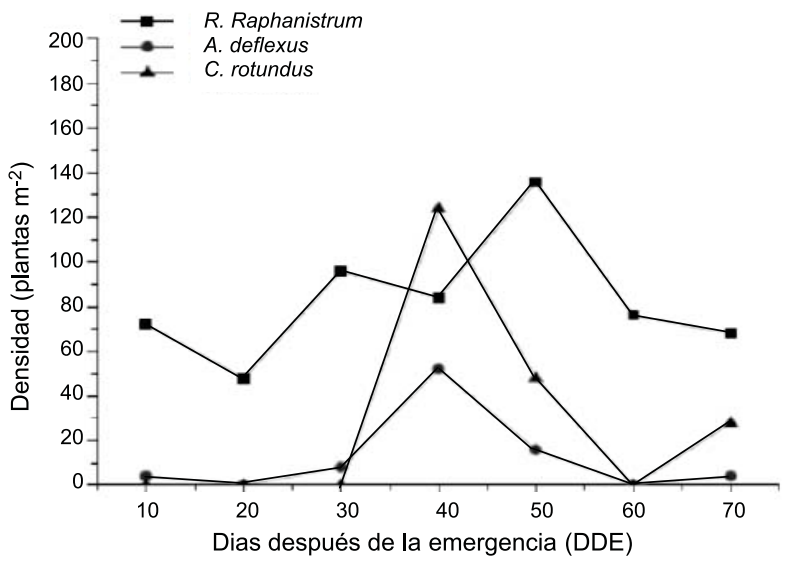

Figura 2 - Densidad de las principales malezas (plantas $\mathrm{m}^{-2}$ ) en función de períodos de convivencia con el frijol en ausencia y presencia de residuos vegetales de crotalaria.

La acumulación máxima de seco se verificó en las dos áreas a los $70 \mathrm{DDE}$ con la especie Raphanus raphanistrum y alcanzó valores de $2.366,3 \mathrm{~g} \mathrm{~m}^{-2}$ y $4.429,4 \mathrm{~g} \mathrm{~m}^{-2}$ en ausencia y presencia de residuos vegetales de crotalaria, respectivamente (Figura 3). Raphanus raphanistrum posee gran capacidad de competencia, suele infestar de modo intenso los cultivos, especialmente de cereales de invierno (Kissmann y Groth, 1999).

Las producciones de frijol iniciales estimadas en la ausencia y en la presencia de residuos vegetales de crotalaria fueron de $1.521,41, \mathrm{y} 1.737,08 \mathrm{~kg} \mathrm{ha}^{-1}$. Con el aumento del peso seco de las malezas, que alcanzaron valores de 713,1 y $1.122,8 \mathrm{~g} \mathrm{~m}^{-2}$ a los $80 \mathrm{DDE}$, los rendimientos disminuyeron para 617,09 y $958,25 \mathrm{~kg} \mathrm{ha}^{-1}$, respectivamente (Figura $4 \mathrm{y}$ Tabla 3). El mismo comportamiento fue verificado por Salgado et al. (2007) en el cultivo de frijol en siembra convencional y por Kozlowski et al. (2002) en siembra directa. Ambos constataron una disminución acentuada de la producción de frijol cuando él convivió por períodos crecientes con la comunidad de malas hierbas.

\section{Ausencia de residuos vegetales}

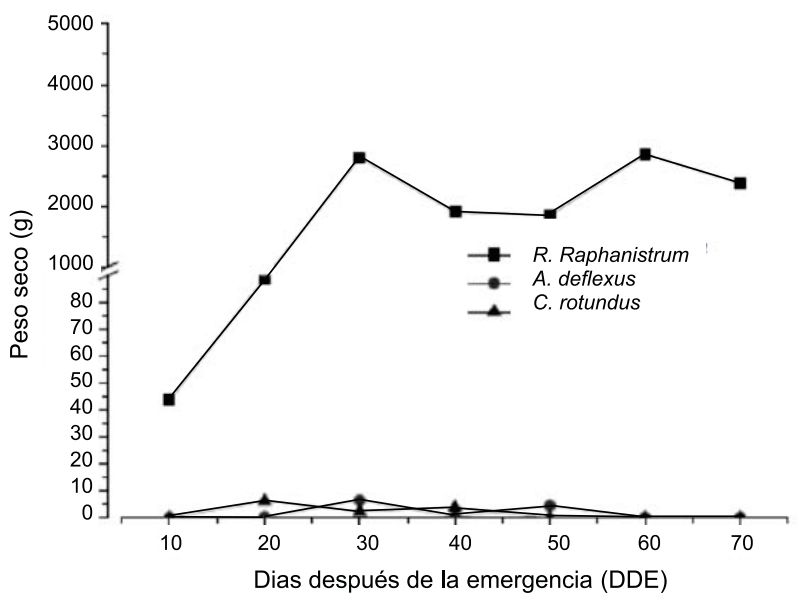

Presencia de residuos vegetales

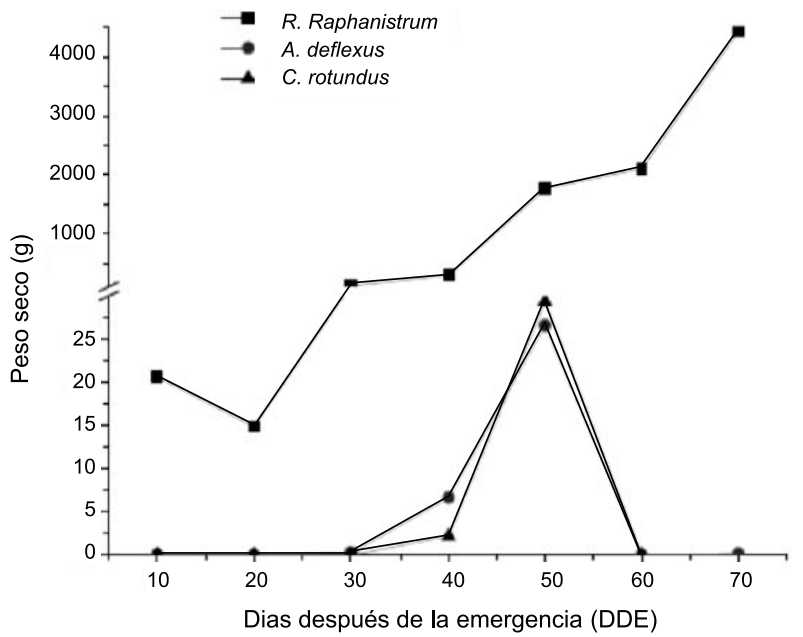

Figura 3 - Peso seco de las principales malezas $\left(\mathrm{g} \mathrm{m}^{-2}\right.$ ) en función de los períodos de convivencia con el frijol en ausencia y en la presencia de residuos vegetales de crotalaria. 

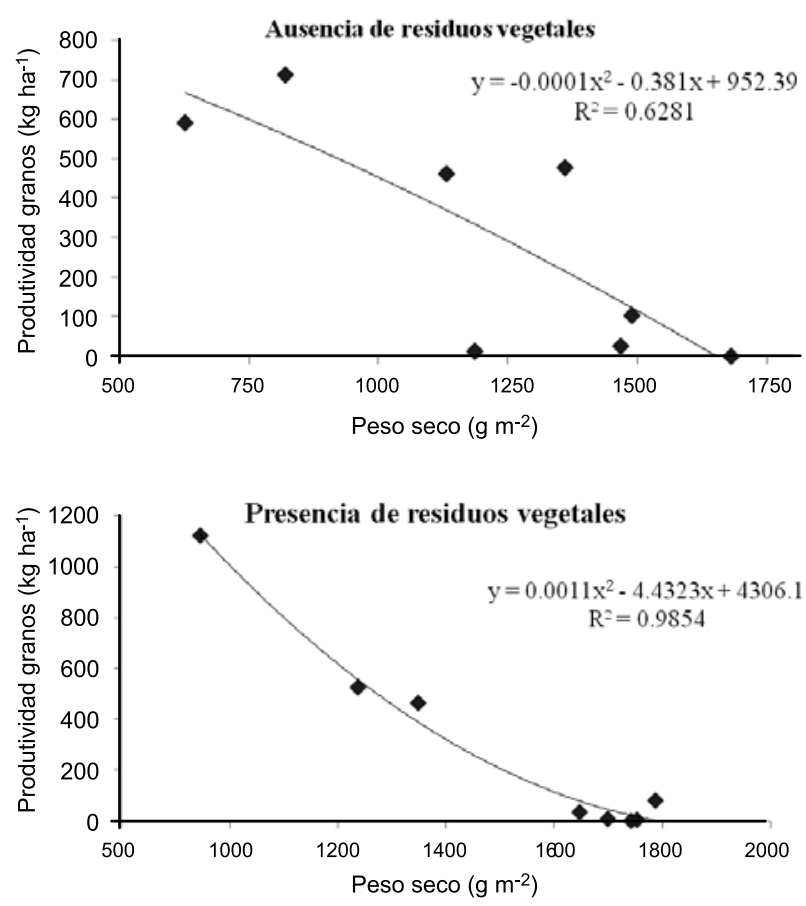

Figura 4 - Correlación entre peso seco $\left(\mathrm{g} \mathrm{m}^{-2}\right)$ de la comunidad infestante al final de los períodos de convivencia y la productividad de granos de frijol $\left(\mathrm{kg} \mathrm{ha}^{-1}\right)$ en función de los períodos de convivencia, en la ausencia y presencia de residuos vegetales de crotalaria, siendo y la máxima productividad de granos de frijol; y x la máxima cantidad de peso seco de malezas.

Se constató pérdida de $40,6 \%$ y $55,1 \%$ en la productividad del frijol cuando se la compara con la obtenida en la ausencia total de las malezas - testigo deshierbado $\left(1.521,41 \mathrm{~kg} \mathrm{ha}^{-1}\right.$, $1.737,08 \mathrm{~kg} \mathrm{ha}^{-1}$ ) -, con la obtenida en la presencia de ellas durante todo el ciclo - testigo enmalezado $\left(617,09 \mathrm{~kg} \mathrm{ha}^{-1}, 958,25 \mathrm{~kg} \mathrm{ha}^{-1}\right)$, en la ausencia y presencia del residuo vegetal de abono verde, respectivamente (Tabla 3).

La producción de frijol era mayor cuando había presencia de residuos vegetales en el área. Este hecho ocurrió a causa de la mayor disponibilidad de $\mathrm{N}$ en razón de la presencia de crotalaria. Posiblemente ésta influyó en el mayor desarrollo del sistema radical y llevó a un mejor aprovechamiento de $\mathrm{N}$ y de otros nutrientes del suelo (Muraoka et al., 2002).

Para el frijol común, la disminución del rendimiento de granos alcanzó 67\% (Salgado et al., 2007) en el sistema convencional. Para la siembra directa con residuos vegetales en el área, Kozlowski et al. (2002) observaron pérdida de $71 \%$ da producción del cultivo, cuando las malezas estuvieron presentes durante todo el ciclo.

Farinelli et al. (2006) obtuvieran mayor productividad, superior a $1.800 \mathrm{~kg} \mathrm{ha}^{-1}$ en el cultivo de frijol, cuando se utilizó abono verde como cobertura vegetal, en sistema de siembra directa en el año 2003. En el año 2004, en los dos sistemas, la materia seca, el nivel foliar de $\mathrm{N}$ y granos por vaina en el cultivo fueron superiores, cuando comparadas a la ausencia de cobertura muerta, en sistema convencional. La productividad del maíz fue significativamente mayor cuando se estableció una rotación de cultivo maíz-crotalaria-maíz. (Silva et al., 2006).

En sistema de siembra directa, con la crotalaria como cobertura vegetal, la materia seca, peso de 100 granos, y principalmente la productividad fueron mayores con relación a la cobertura muerta de maíz, mijo, arroz, mucuna-negra y maíz con mucuna-negra (Silva et al., 2003).

Respecto al peso de cien semillas de frijol, no se constataron diferencias significativas

Tabla 3 - Parámetros determinados para las ecuaciones sigmoidales de Boltzman ajustadas a los datos de productividad de granos en función de los períodos de convivencia con las malezas para el cultivo de frijol

\begin{tabular}{|c|c|c|}
\hline \multirow{2}{*}{ Parámetro } & \multicolumn{2}{|c|}{ Residuos vegetales de crotalaria } \\
\cline { 2 - 3 } & Ausencia & Presencia \\
\hline $\mathrm{A}_{1}$ & $1.521,41$ & $1.737,08$ \\
\hline $\mathrm{A}_{2}$ & 617,09 & 958,25 \\
\hline $\mathrm{X}_{0}$ & 51,50 & 53,70 \\
\hline $\mathrm{dx}$ & 7,30 & 6,80 \\
\hline $\mathrm{R}^{2}$ & 0,91 & 0,89 \\
\hline
\end{tabular}

$y=\frac{(A 1-A 2)}{1+e^{(X-X o) / d x}}+A 2 \quad$ Ecuación (Boltzman)

Obs.: $y$ (productividad de granos de frijol en función de los períodos de convivencia), A1 (producción máxima obtenida en las plantas que fueron mantenidas limpias durante todo el ciclo), A2 (producción mínima obtenida en las plantas enmalezadas durante el período máximo de 93 días), X (límite superior del período de convivencia), $\mathrm{X}_{0}$ (límite superior del período de convivencia, que corresponde al valor intermedio entre la producción máxima y la mínima), dx (parámetro que indica la velocidad de pérdida de producción en función del tiempo de convivencia) y $\mathrm{R}^{2}$ (coeficiente de regresión). 
en este componente de producción, que se mantuvo entre 22 y 26 g. Se obtuvieron resultados similares por Parreira et al. (2011), con frijol plantado en sistema convencional. Sin embargo, Silva et al. (2003) obtuvieran peso mayor de 100 granos, en media $23 \mathrm{~g}$ con uso de Crotalariajuncea.

El período anterior a la interferencia (PAI) fue de 29 y 38 días después de la emergencia para el cultivo de frijol en ausencia y presencia de residuos vegetales de crotalaria, respectivamente (Figura 5). El mayor PAI ocurrió en el área que contenía residuos vegetales de abono verde, debido al hecho de que, con mayor disponibilidad de nutrientes provenientes de la crotalaria, las plantas de frijol se desarrollaron más rápidamente, sombrearon el área y ocuparon un espacio mayor, lo que no permitió el establecimiento de malezas en el área. Independiente de esto, Victoria Filho (1985) relató que el período más importante de la competencia de malezas y el frijol se sitúa generalmente entre $20^{\circ}$ y $30^{\circ}$ día después de la emergencia del cultivo

Miyazawa et al. (1993) consideraron que, en sistemas de rotación, el cultivo sucesor puede beneficiarse respecto a la fertilidad del suelo con los residuos vegetales durante la fase inicial, sobre todo aquellos de menor relación $\mathrm{C} / \mathrm{N}$, porque son los más eficientes en la neutralización de $\mathrm{H}^{+}$.

Freitas et al. (2009) verificaron que, en el sistema convencional, el cultivo de frijol caupí en el cultivar BR 16 registró un período anterior a la interferencia de 11 dias. Mattos et al. (1991), por su parte, en ese mismo cultivo y condiciones, encontró un PAI desde la emergencia hasta 36 días después y mostró que resultados variados en un mismo cultivo son frecuentes.

Salgado et al. (2007) obtuvieron un PAI de 17 dias al utilizar el frijol carioca común en sistema convencional sin residuos vegetales. Kozlowski et al. (2002), en área con residuos vegetales, en siembra directa, obtuvieron un PAI de 36 dias, que corresponde a la segunda hoja trifoliada de la planta de frijol y demuestra que este sistema de producción extiende el Período Anterior a la Interferencia de las malezas sobre el frijol.

Las plantas de frijol pueden convivir con una comunidad de malezas, entre las que sobresalen $R$. raphanistrum, A. deflexus, C. rotundus y $D$. horizontalis hasta 29 y 38 dias después de su emergencia, con ausencia y presencia de residuos vegetales de crotalaria, respectivamente.

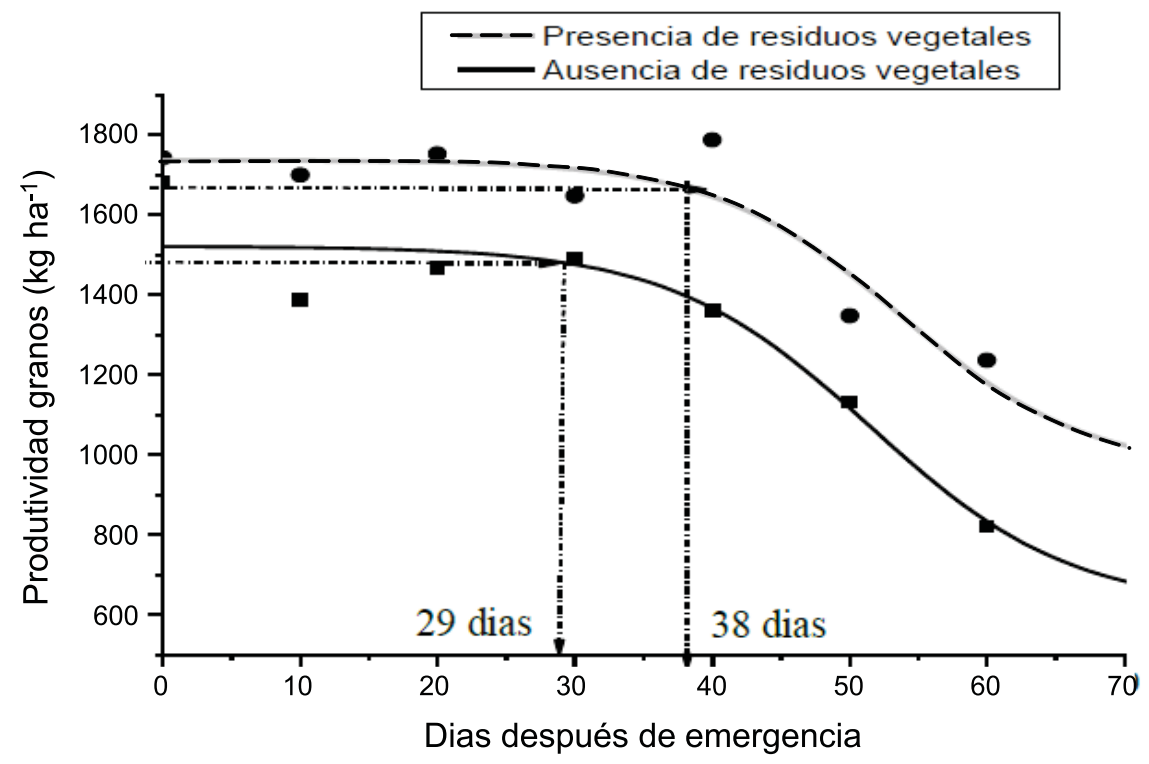

Figura 5 - Productividad de granos del cultivo de frijol $\left(\mathrm{kg} \mathrm{ha}^{-1}\right)$, en ausencia y presencia de residuos vegetales de crotalaria, como respuesta a los períodos de convivencia con las malezas. 
Las malezas presentes durante todo el ciclo del frijol provocaron pérdidas de 40,6\% y $55,1 \%$ de la producción, en ausencia y presencia de residuos vegetales de crotalaria, respectivamente.

\section{LITERATURA CITADA}

ALVARENGA, R. C. et al. Características de alguns adubos verdes de interesse para a conservação e recuperação de solos. Pesq. Agropec. Bras., v. 30, n. 1, p. 175-185, 1995.

BOWMAN, D. C.; CHERNEY, C. T.; RUFTY JUNIOR, T. W. Fate and transport of nitrogen applied to six warmseason turfgrasses. Crop. Sci., v. 42, n, 1 p. 833-841, 2002.

CARROW, R. N.; WADDINGTON, D. V.; RIEKE, P. E. Turfgrass soil fertility and chemical problem: assessment and management. Chelsea: Ann Arbor, 2001. 400 p.

COBUCCI, T.; STEFANO, J. G.; KLUTHCOUSKI, J. Manejo de plantas daninhas na cultura do feijoeiro em plantio direto. Santo Antônio de Goiás: Embrapa Arroz e Feijão, 1999. 56 p. (Circular Técnica, 35).

ESPINDOLA, J. J.A.; GUERRA, G.M.; ALMEIDA, D.L; TEIXEIRA, M.G; Urquiaga, S. Evaluation of perennial herbaceous legumes with different phosphorous sources and levels in a Brasilian Utisol. Renewable Agriculture and Food Systems, v. 20, n. 1, p. 56-62, 2005.

FARINELLI, R. et al. Adubação nitrogenada de cobertura no feijoeiro, em plantio direto e convencional. Pesq. Agropec. Bras., v. 41, n. 2, p. 307-312, 2006.

FREITAS, F. C. L. et al. Interferência de plantas daninhas na cultura do feijão-caupi. Planta Daninha, v. 27, n. 2, p. 241-247, 2009.

GONÇALVES, C. N.; CERETA, C. A.; BASSO, C. J. Sucessões de culturas com plantas de cobertura e milho em plantio direto e sua influência sobre o nitrogênio do solo.

R. Bras. Ci. Solo, v. 24, n. 1, p. 153-159, 2000.

KISSMANN, K. G.; GROTH, D. Plantas infestantes e nocivas. 2.ed. São Paulo: BASF, 1999. 978 p.

KOZLOWSKI, L. A. et al. Período crítico de interferência das plantas daninhas na cultura do feijoeiro-comum em sistema de semeadura direta. Planta Daninha, v. 20, n. 2, p. 213-220, 2002.

KUVA, M. A. et al. Períodos de interferência das plantas daninhas na cultura da cana-de-açúcar. I - Tiririca. Planta Daninha, v. 18, n. 2, p. 241-251, 2000.

JAKELAITIS, A. et al. Dinâmica populacional de plantas daninhas sob diferentes sistemas de manejo nas culturas de milho e feijão. Planta Daninha, v. 21, n. 1, p. 71-79, 2003.
LORENZI, H. Manual de identificação e controle de plantas daninhas: plantio direto e convencional. 6.ed. São Paulo: Instituto Plantarum, 2006. 339 p.

LUNKES, J. A. Manejo integrado de plantas daninhas na cultura do feijão. In: FANCELLI, A. L.; DOURADO-NETO, D. Tecnologia da produção do feijão irrigado. Piracicaba: ESALQ/USP, Departamento de Agricultura, 1997. p. 9-19.

MALAVOLTA, E. ABC da adubação. São Paulo: Ceres, 1979. 255 p.

MATTOS, V. P.; SILVA, R. F.; VIEIRA, C.; SILVA, J. S. Período crítico de competição entre plantas daninhas e a cultura do caupi. Pesq. Agropec. Bras., v. 26, n. 5. p. 737-743, 1991.

MESCHEDE, D. K. et al. Período crítico de interferência em soja: estudo de caso com baixa densidade de estande e testemunhas duplas. Planta Daninha, v. 22, n. 2, p. 239-246, 2004.

MIYAZAWA, M.; PAVAN, M. A.; CALEGARI, A. Efeito de material vegetal na acidez do solo. R. Bras. Ci. Solo, v. 17, n. 3, p. 411-416, 1993.

MUELLER-DOMBOIS, D.; ELLEMBERG, H. Aims and methods of vegetation ecology. New York: Willey \& Sons, 1974. 547 p.

MURAOKA, T. et al. Eficiencia de abonos verdes (crotalaria y mucuna) y urea, aplicadas solos o juntamente, como fuentes de N para el cultivo de arroz. Terra, v. 20, n. 1, p. 17-23, 2002.

PARREIRA, M. C.; ALVES, P. L. C. A.; PENAHERRERACOLINA, L. A. Influencia de las malezas sobre el cultivo de frijol en función de espaciamiento y de la densidad de plantas. Planta Daninha, v. 29, n. 4, p. 829-835, 2011.

PITELLI, R. A. Interferências de plantas daninhas em culturas agrícolas. Inf. Agropec., v. 11, n. 129, p. 16-27, 1985.

PITELLI, R. A.; DURIGAN, J. C. Terminologia para períodos de controle e de convivência das plantas daninhas em culturas anuais e bianuais. In: CONGRESSO BRASILEIRO DE HERBICIDAS E PLANTAS DANINHAS, 15., 1984, Belo Horizonte. Resumos... Piracicaba: SBHED, 1984. p. 37.

SALGADO, T. P. et al. Interferência das plantas daninhas no feijoeiro carioca. Planta Daninha, v. 25, n. 3, p. 443-448, 2007.

SCHOLTEN, R.; PARREIRA, M. C.; ALVES, P. Período anterior à interferência das plantas daninhas para a cultivar de feijoeiro 'Rubi' em função do espaçamento e da densidade de semeadura. Acta Sci. Agron., v. 33, n. 2, p. 313-320, 2011. 
SEVERINO, F. J.; CHRISTOFFOLETI, P. J. Efeitos de quantidades de fitomassa de adubos verdes na supressão de plantas daninhas. Planta Daninha, v. 19, n. 2, p. 223-228, 2001.

SILVA, E. C. et al. Aproveitamento do nitrogênio $\left({ }^{15} \mathrm{~N}\right)$ da crotalária e do milheto pelo milho sob plantio direto em Latossolo Vermelho de cerrado. Ci. Rural, v. 36, n. 3, p. 739-746, 2006.

SILVA, T. R. B.; ARF, O.; SORATTO, R. P. Adubação nitrogenada e resíduos vegetais no desenvolvimento do feijoeiro em sistema de plantio direto. Acta Sci. Agron., v. 25, n. 1, p. 81-87, 2003.
VICTORIA FILHO, R. Potencial de concorrência de plantas daninhas em plantio direto. In: FUNDAÇÃO CARGILL. Atualização em plantio direto. Campinas: 1985. p. 31.

VINCENSI, M. M. et al. Manejo do solo e adubação nitrogenada na supressão de plantas daninhas na cultura do feijão de inverno e irrigado. R. Ci. Agron., v. 42, n. 3, p. 758-764, 2011.

WILLIAN, R. D. Fisiologia das plantas eficientes $\left(\mathrm{C}_{4}\right)$ e ineficientes $\left(\mathrm{C}_{3}\right)$. In: WARREN, G. F. et al. Curso Intensivo de Controle de Ervas Daninhas. Viçosa, MG: Universidade Federal de Viçosa, 1973. p. 68-79. 